\title{
A New Principle of Cell Sorting by Using Selective Electroporation in a Modified Flow Cytometer
}

\author{
Tom C. Bakker Schut, Bart G. de Grooth, and Jan Greve \\ Department of Applied Physics, Cell Characterization Group, University of Twente, \\ 7500 AE Enschede, The Netherlands
}

Received for publication March 2, 1989; accepted March 10, 1990

\begin{abstract}
When a strong electric field pulse of a few microseconds is applied to biological cells, small pores are formed in the cell membranes; this process is called electroporation. At high field strengths and/or long pulse durations the membranes will be damaged permanently. This eventually leads to cell kill.

We have developed a modified flow cytometer in which one can electroporate individual cells selected by optical analysis. The first experiments with this flow cytometer were designed to use it as a damaging sorter; we used electric pulses of $10 \mu \mathrm{s}$ and resulting field strengths of 2.0 and $3.2 \times 10^{6} \mathrm{~V} / \mathrm{m}$ to kill $\mathrm{K} 562$ cells and lymphocytes respectively. The hydrodynamically focused cells are first optically analyzed in the usual way in a square flow channel. At the end of this channel the
\end{abstract}

cells are forced to flow through a small Coulter orifice, into a wider region. If optical analysis indicates that a cell is unwanted, the cell is killed by applying a strong electric field across the Coulter orifice. The wanted living cells can be subsequently separated from the dead cells and cell fragments by a method suitable for the particular application (e.g., centrifugation, cell growth, density gradient, etc.).

The results of these first experiments demonstrate that by using very simple equipment, sorting by selective killing with electric fields is possible at rates of $1,000 \mathrm{cells} / \mathrm{s}$ with a purity of the sorted fraction of $99.9 \%$.

Key terms: Flow cytometry, Coulter counter, electrodamaging
Flow cytometers can be equipped with sorting devices to sort out cells selected by analysis. Four different types of sorters can be distinguished $(2,8)$; the hydraulic fluid switch sorter, the acoustic fluid switch sorter, the droplet sorter, and the photodamaging sorter. The two fluid switch sorters have a low sorting rate, less than 500 cells per s, but they are closed systems (no contamination of the sample or the surroundings) and easy to operate. The droplet sorter has a high sorting rate (normally 1,000 to 5,000 cells per $s$ but 20,000 is possible) (6) but it is an open system and not easy to operate. The photodamaging sorter has a very high sorting rate $(30,000$ cells per $s$ has been achieved) (6); it is a closed system and easy to operate. The equipment, however, is expensive and the cells have to be photosensitized before sorting; because of the damaging principle only certain types of cells can be sorted out and kept alive (2).

In this study we describe a new principle of cell sorting by using selective electroporation (or electropermeabilization) in a modified flow cytometer. Like the pho- todamaging sorter the electroporating sorter is a damaging sorter but the equipment is much cheaper compared to the photodamaging sorter and there is no need to stain the cells.

\section{THEORY}

A cell membrane of a cell in an electrolytic solution can be regarded as an isolator separating two conducting media. Assuming that the conductivity of the membrane is small compared to the conductivity of the interior and exterior of the cell and that the membrane thickness is small compared to the radius of the cell, the potential across the membrane, $V_{m}=V_{b}-V_{a}$ (see Fig. 1A), for a spherical cell in a homogeneous static electric field is in good approximation given by (10):

$$
\mathrm{V}_{\mathrm{r}}=\frac{3}{3} \cdot \mathrm{E}_{\mathrm{o}} \cdot \mathrm{r} \cdot \cos \theta
$$

$\mathrm{E}_{\mathrm{o}}=$ field strength of the applied electric field,

$\mathbf{r}=$ radius of the cell,

$\theta=$ angle between the radius vector and the direction of the electric field. 

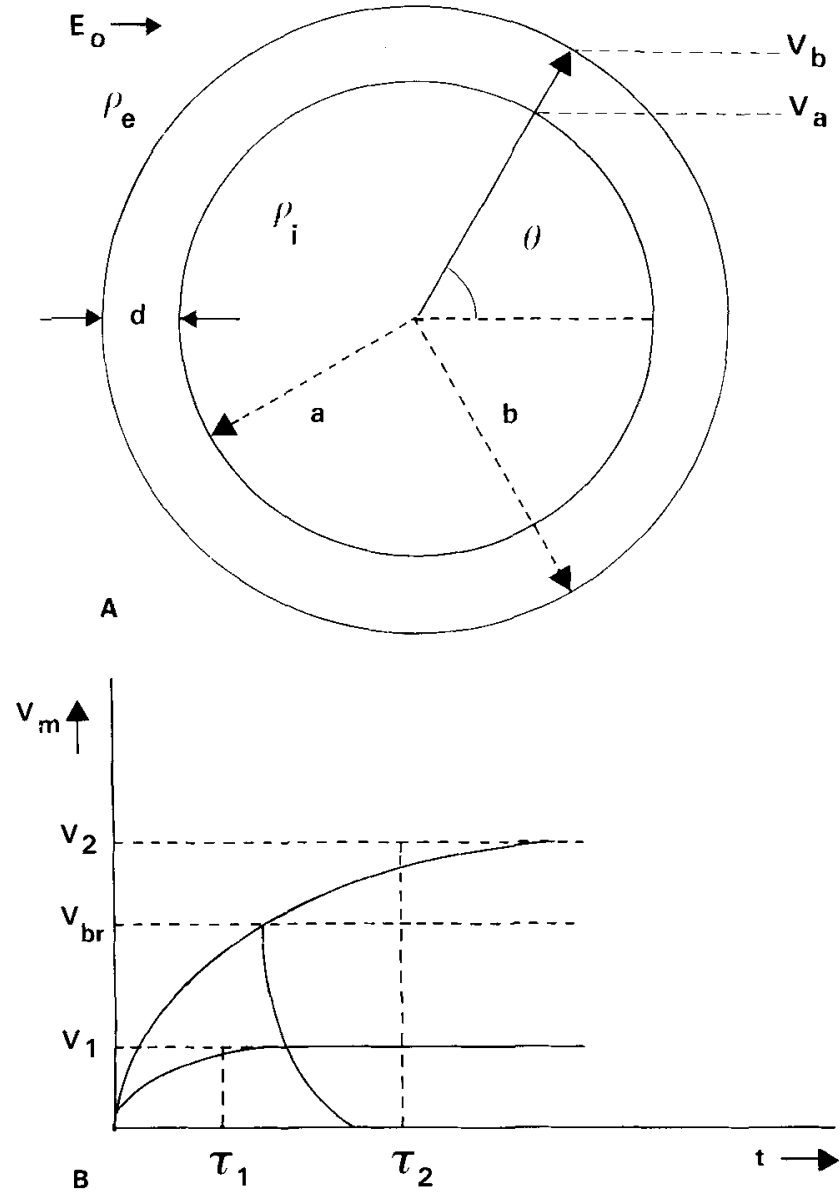

FIG. 1. A: Model for a spherical cell in an electric field and definition of the relevant parameters; $a$ is radius of the cell; $\mathbf{E}_{0}$ is fieldstrength of the applied electric field; $a$ is inner radius of the cell; $b$ is the outer radius; $\theta$ is the angle between the radius vector and the direction of the electric field; $V_{m}$ is $V_{b}-V_{a}$, the potential across the membrane. B: Time responses of the membrane voltage to step functions of the applied electric field below and above the critical value at which breakdown occurs; $\mathrm{V}$ is membrane voltage; $\mathrm{V}_{\mathrm{br}}$ is the breakdown-voltage; $\tau=$ relaxation-time of the membrane

For the field strength inside the membrane one obtains:

$$
\mathrm{E}_{\mathrm{m}}=\frac{\mathrm{V}_{\mathrm{m}}}{\mathrm{d}}=\frac{3}{2} \cdot \mathrm{E}_{0} \cdot \frac{\mathrm{r}}{\mathrm{d}} \cdot \cos \theta
$$

$\mathrm{d}=$ thickness of the membrane.

For a cell with a radius of $5 \mu \mathrm{m}$ and a membranethickness of $5 \mathrm{~nm}$ one calculates:

$$
E_{m}=1,500 \cdot E_{o} \cdot \cos \theta .
$$

Thus, the field in the membrane can be more than a thousand times stronger than the applied field.

Because of the membrane capacity the field in the membrane cannot follow an applied field instantaneously (see Fig. 1B); the relaxation-time $\tau$ is given by (10):

$$
r \cdot C_{m} \cdot\left(\rho_{i}+0.5 \cdot \rho_{e}\right)
$$

$\mathrm{C}_{\mathrm{m}}=$ specific capacity of the membrane,

$\rho_{\mathrm{i}}=$ specific resistance of the interior of the cell,

$\rho_{e}=$ specific resistance of the exterior of the cell.

Under physiological circumstances this relaxation time of membranes is in the range of 10-1,000 (10), e.g., if $\mathrm{r}=5 \mu \mathrm{m}, \mathrm{C}_{\mathrm{m}}=1 \cdot 10^{-2} \mathrm{~F} / \mathrm{m}^{2}, \rho_{\mathrm{i}} \approx \rho_{\mathrm{e}} \approx 0.7 \Omega \mathrm{m}$ (physiological salt solution), then $\tau \approx 53 \mathrm{~ns}$. Therefore the expression for the membrane voltage holds even for very short pulse durations.

If the membrane potential exceeds a critical value, electrical breakdown of the cell membrane occurs. The breakdown voltage $\left(\mathrm{V}_{\mathrm{br}}\right.$, see Fig. 1B) for a typical lipid bilayer membrane is about $1.0 \mathrm{~V}(10)$; for a membrane thickness of $5 \mathrm{~nm}$ the field-strength in the membrane is $2 \times 10^{8} \mathrm{~V} / \mathrm{m}$. Due to the electrical breakdown numerous small pores are formed in the membrane (electroporation). This pore formation can be reversible or irreversible. In the first case the pores close and the cell stays alive. In the second case the pores don't close and the cell dies eventually; because of the membrane rupture the cell can even burst and be destroyed totally (7).

Whether a cell dies or not depends upon the pulse height and pulse duration, but also on external factors such as the composition of the external medium, temperature, etc. $(4,10)$.

\section{MATERIALS AND METHODS Cells}

K562 cells (erythroblasts) were maintained as suspension cultures in RPMI $1640+10 \%$ fetal calf serum at $37^{\circ} \mathrm{C}$ in a humidified atmosphere of $5 \% \mathrm{CO}_{2}$ in air. Human lymphocytes were isolated from peripheral blood of healthy donors by using the Ficoll-Paque method (1). For the experiments K562 cells and lymphocytes were suspended in RPMI $1640+10 \%$ fetal calf serum and PBS respectively; they were kept at room temperature for a few hours and their viability was regularly checked.

\section{Measurement of Cell Viability}

To examine cell viability immediately after the pulse experiments, the pulsed sample (cells in $0.9 \% \mathrm{NaCl}$ ) was centrifuged ( $5 \mathrm{~min}, 10 \mathrm{~g}$ ) and the pellet was stained with a solution of $3 \mu \mathrm{g} / \mathrm{ml}$ acridine orange and $10 \mu \mathrm{g} / \mathrm{ml}$ ethidium bromide. The percentage of living cells was determined with a fluorescence microscope (Nikon, type Optiphot EF). Since cells can burst and disintegrate after electroporation (7), we counted the percentage of living cells relative to a number of fluorescent microspheres (diameter $=5 \mu \mathrm{m}$, Polysciences Inc., Warrington, FL, USA) added to the sample before electroporating. The sample was regularly stirred to keep it homogeneous. The percentage of cells that survive a pulse of $V_{p}$ volt is thus given by:

$$
\mathrm{S}\left(\mathrm{V}_{\mathrm{p}}\right)=\frac{\left(\frac{\text { number of counted live cells }}{\text { number of counted spheres }}\right) \mid \mathrm{v}_{\mathrm{p}} \mathrm{Volt}}{\left(\frac{\text { number of counted live cells }}{\text { number of counted spheres }}\right) \mid 0 \text { Volt }} \cdot 100 \%
$$




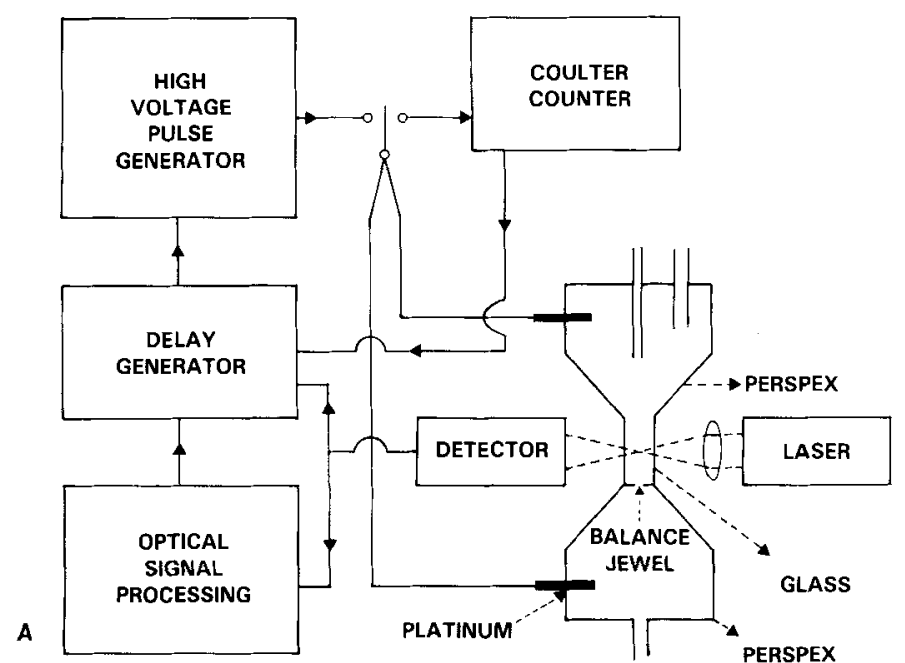

FIG. 2. A: Schematic drawing of the configuration used in the first experimental setup; relevant measures of the flow cell are given in the text. Cells are detected by using forward light scattering and killed by applying an electric field pulse at the moment the cell is inside the orifice; the delay between optical detection and the moment

\section{Flow Cytometer}

A schematic drawing of the first configuration used is shown in Figure 2A. The flow cell exists of two (relatively) large compartments (made out of perspex: internal radius $=2.5 \mathrm{~mm}$, length $=20 \mathrm{~mm}$ ) that are connected by a flow channel and a Coulter orifice. The first compartment has a conic part to achieve hydrodynamic focusing; the flow channel is a precision square glass capillary, $400.400 \mu^{2}, 4.2 \mathrm{~mm}$ long (Vitro dynamics Inc., Rockaway, NJ, USA). The Coulter orifice is a balance jewel, diameter of $70 \mu \mathrm{m}$, length of $100 \mu \mathrm{m}$ (Seitz original, Seitz, Switzerland). Both compartments were provided with platinum electrodes (cylindric, diameter $=1 \mathrm{~mm}$, length $=2 \mathrm{~mm}$ ). Sheath and sample flow were regulated in a positive pressure system; for sheath flow we used a physiological salt solution $(0.9 \%$ $\mathrm{NaCl}$ ).

Light from a $5 \mathrm{~mW}$ HeNe-laser (Spectra Physics, San Jose, CA, USA) with $\lambda=632.8 \mathrm{~nm}$ polarized parallel to the direction of flow was expanded by using two spherical lenses with focal lengths of 10 and $40 \mathrm{~mm}$ and then focused to an elliptic spot of approximately $1.6 \mu \mathrm{m}$ in the direction of flow and $100 \mu \mathrm{m}$ in the direction orthogonal to flow with a cylindrical lens (focal length of $80 \mathrm{~mm}$ ) and a Leitz 32/0.40 objective. Forward light
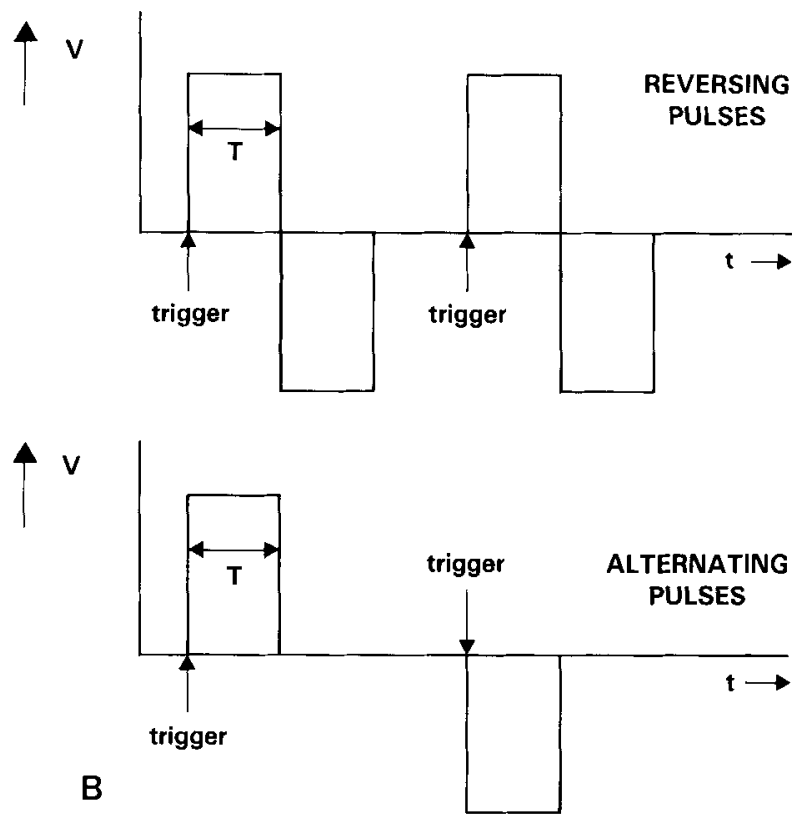

at which the cell is inside the orifice is determined by using the flow cell as a Coulter counter and measuring the time difference between the optical and Coulter counter signal. B: Reversing and alternating pulses. ( $\mathrm{T}$ is the pulse duration; $\mathrm{V}$ is the pulse-height).

scattering $\left(1.5^{\circ}\right.$ to $\left.15^{\circ}\right)$ was collected with a spherical lens (focal length $40 \mathrm{~mm}$ ) provided with a rectangular beam stop; the light was detected with a photo diode (model pin 10D, United Detector Technology).

After hydrodynamic focusing and optical analysis in the square channel the cells flow through the Coulter orifice. At that moment a high-voltage pulse $(0-1,000$ $\mathrm{V}$, pulse duration $100 \mu \mathrm{s}$, rise time at $500 \mathrm{~V}=2 \mu \mathrm{s}$ ) can be applied to the electrodes which results in a strong electric field inside the orifice. The high-voltage pulse generator is homemade and can generate two types of pulses, reversing and alternating (see Fig. 2B); both positive and negative pulses are used to prevent the formation of gas $\left(\mathrm{H}_{2}\right.$ and $\left.\mathrm{Cl}_{2}\right)$ at the electrodes.

If a cell is to be pulsed, a processing signal is first delayed by a home-built delay generator, based on a TDA 1022 delay line for analog signals, and then supplied to the pulse generator. The delay between the optical detection and the moment a cell is in the orifice is about $1.5 \mathrm{~ms}$; it is not the same for all the cells because of slight variations in flow speed and jitter in the electronically generated delay. To ensure that all selected cells are pulsed, the pulse duration had to be made longer than the actual time a cell is inside the orifice.

The delay time between the optical analysis and the moment that the electric field has to be applied across 
the orifice can be determined by using the flow cell as a Coulter counter and measuring the time difference between the optical signal and the Coulter counter signal. The Coulter counter signal was not used to trigger the high-voltage pulse because then the cell is already inside the orifice when the pulse is given, which means that the effective pulse duration decreases.

A second, improved, version of this flow cytometer was built in order to be able to measure orthogonal scatter and fluorescence signals and to reduce the delay between analysis and killing. The square glass capillary was replaced by a flow cell (made by Hellma $\mathrm{Gmbh}$, West Germany) with a conic part of $4 \mathrm{~mm}$ and a flow channel of $1 \mathrm{~mm}$. Light from a $100 \mathrm{~mW}$ argon laser (model 5500 AWC, Ion Laser Technology, Salt Lake City, UT, USA) with $\lambda=488 \mathrm{~nm}$, polarized parallel to the direction of flow, was focused to an elliptic spot of approximately $4.9 \mu \mathrm{m}$ in the direction of flow and $100 \mu \mathrm{m}$ in the direction orthogonal to flow by using a cylindrical lens (focal length of $80 \mathrm{~mm}$ ) and a Leitz $32 / 0.40$ objective. Forward light collection was the same as in the first flow cytometer. Orthogonal scatter (maximum collecting angle $=113^{\circ}$, minimum collecting angle $=67^{\circ}$ ) and fluorescence were collected by using a Leitz 32/0.40 objective and detected by using photomultipliers (Hammamatsu R1104). Fluorescence was separated from scattered light by using a dichroic mirror (Ealing, no. 35-5347) at an angle of $45^{\circ}\left(\lambda_{\text {cut-off }} \simeq\right.$ $510 \mathrm{~nm}$ ) and a KV 520 colored glass filter (Schott, Tiel, The Netherlands). Green fluorescence was separated from red by using a dichroic mirror (Ealing, no. 35$5420)$ at an angle of $45^{\circ}\left(\lambda_{\text {cut-off }} \simeq 590 \mathrm{~nm}\right)$ and filtered with an OG 530 colored glass filter (Schott, Tiel, The Netherlands). Red fluorescence was filtered by using a RG 610 colored glass filter (Ealing). The intensities of the two light scatter signals and the two fluorescence signals of each separate cell were digitized and stored in list mode with a personal computer (model Sirex AT, Sirex, Enschede, The Netherlands) by direct memory access by using a homemade analog signal-processing unit, an RTI800 interface-card (Analog devices, Northwood, MA, USA), and a home-written software program. Window discriminators were used to select cells with certain scatter and/or fluorescence properties. The output of these discriminators was delayed by a home-built digital delay generator and then supplied to the pulse generator. The delay in this cytometer was about $200 \mu \mathrm{s}$; the pulse time we used was $50 \mu \mathrm{s}$.

\section{RESULTS}

In the electroporating sorter each individual cell is optically analyzed in a quartz flow channel; if it is an unwanted cell it is killed by applying an electric field pulse at the moment the cell passes the orifice. In the first experiment, described here, we examined the effectiveness of the killing process. The flow velocity inside the Coulter orifice in all these experiments was about $10 \mathrm{~m} / \mathrm{s}$ inside the orifice which means that the time a cell is inside the orifice is about $10 \mu \mathrm{s}$. Since the high-voltage pulse is made much longer than that, this is also the effective pulse duration. The delay time in the first configuration was about $1.5 \mathrm{~ms}$. To ensure that all cells were inside the orifice at the time of the pulse, pulses of $100 \mu$ s duration were used. In order to prevent the formation of gas both reversing and alternating pulses (see Fig. 2B) could be applied to achieve cell lysis. Reversing pulses appeared to be more effective; they have been used in the experiments described so far. The processing rate used in all the experiments lies between 500 and 1,000 cells per s; all experiments and measurements were done at room temperature.

The effectiveness of the killing process as a function of the field strength was examined for K562 cells and for lymphocytes by measuring the survival (defined above) as a function of the applied voltage (see Fig. 3A and $3 \mathrm{~B}$ respectively).

More than $99.9 \%$ of the K562 cells $(15-20 \mu \mathrm{g}$ in diameter) are killed at an applied voltage of $500 \mathrm{~V}$ (Fig. $3 \mathrm{~A}$ ) which can be calculated to give a field strength in the orifice of approximately $2.0 \times 10^{6} \mathrm{~V} / \mathrm{m}$ (see Appen$\operatorname{dix}$ A).

The shape of the curve can be explained by size differences in the K562 population: large cells have a breakdown at lower field strengths than small cells (see eq. $\{1\}$ ).

Figure 3B shows the survival of human lymphocytes (8-10 $\mu \mathrm{m}$ in diameter); more than $99 \%$ are killed at $800 \mathrm{~V}\left(3.2 \times 10^{6} \mathrm{~V} / \mathrm{m}\right)$. The difference in required voltage to kill K562 cells and lymphocytes can be explained by differences in size (see eq. 1); the shape of the curves is essentially the same for both types of cells.

Figure 3C shows that the killing is really caused by the triggered electric fields; if only half the cells are pulsed, only half the cells are killed.

In the experiments with the second improved version we looked at the selectivity of the killing process by only pulsing a selected cell type. All experiments were done with a mixture of K562 cells and human peripheral blood lymphocytes. The sorted fraction was centrifuged and stained. Cells with a high acridine orange content are alive; cells with a high ethidium bromide content are dead. Figure 4 shows the scatter plots of a control sample of a mixture of K562 cells (K) and lymphocytes (L).

Figure 5 shows the scatter plots of the sorted fraction after all K562 cells have been pulsed. Only very few cells can be identified with living K562 cells (less than $1 \%$ of the original amount). The lymphocytes in this sorted fraction are still alive. Figure 6 show the scatter plots of the sorted (and centrifugated) fraction after all lymphocytes have been pulsed. Here the K562 cells are alive and most of the lymphocytes are dead (less than $4 \%$ living cells compared to the original number). We believe that the surviving lymphocytes are not killed because of two reasons. Firstly our sorting electronics did not function fully correctly for the low-input signals. Secondly double cells in the original sample, i.e., 

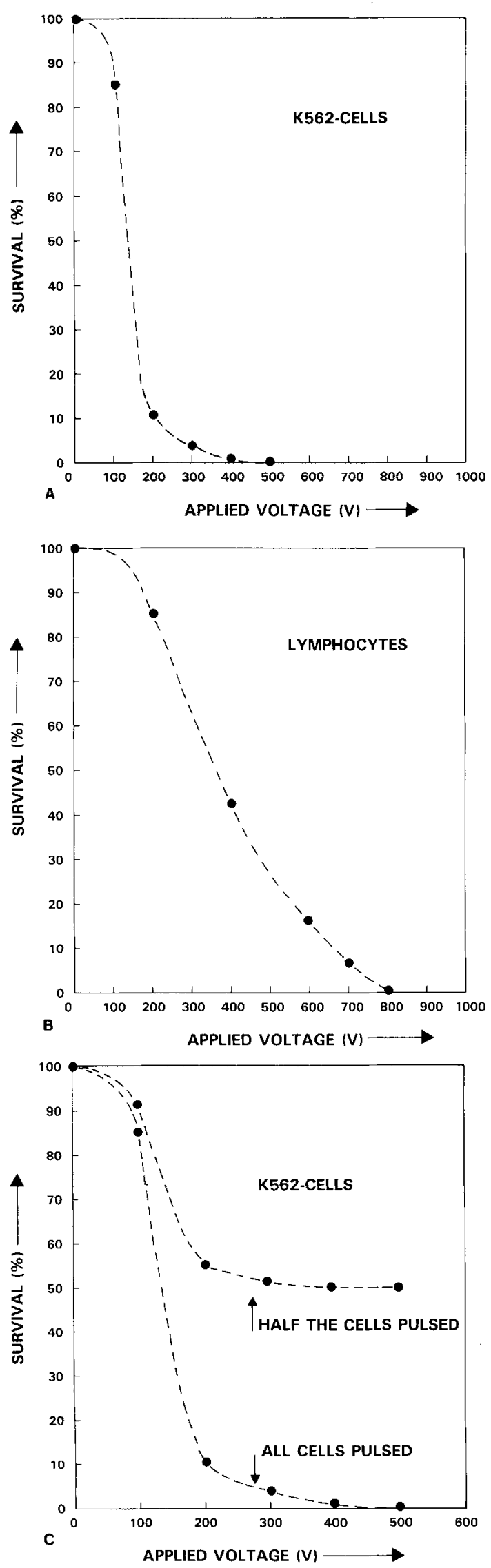

double lymphocytes and K562 lymphocyte combinations, are not recognized as lymphocytes and therefore not killed.

When trying to grow the sorted fractions again in a K562 suspension culture, we found that fractions of which the lymphocytes were killed resumed normal growth within $3 \mathrm{~d}$; fractions of which the K562 cells were killed appeared completely dead after a 3 days (more than $99.9 \%$ dead).

The maximum achievable sorting speed in our sorter is about 5000 cells/second. At this speed $95 \%$ of the K562 population in a mixture of lymphocytes and K562 cells can be killed without killing too many lymphocytes. At 10,000 cells/second still $95 \%$ of the K562 population can be killed but then many lymphocytes (about $50 \%$ ) are killed too. This is due to our sorter logic: when a K562 cell and another cell arrive at the measuring point in a short period of time both get killed.

\section{DISCUSSION}

In this study we have shown a new principle of cell sorting applicable in flow cytometry. Our initial experiments show that sorting rates of 1,000 cells/s with a purity of the sorted fraction of more than $99 \%$ can easily be achieved. The electroporating sorter is a closed system like the fluid switch sorters (8) and the Zapper (3). The electroporating sorter has a high sorting rate like the droplet sorter but the electroporating sorter is much easier to build and operate. The main disadvantage is the fact that it is a damaging sorter. Compared to the other existing damaging sorter, the Zapper, the speed of the electroporating sorter is lower but there is no need for an additional (expensive) laser and, more important, it is not necessary to stain the cells to be able to kill them. Applications for this sorter lie in the same field as for the Zapper, e.g., sorting hybridomas by killing all the unwanted ones (3).

To determine what causes the cell killing one has to consider three different causes: irreversible breakdown of the cell membrane, heat production in the orifice, and shear and/or turbulent forces that act on the cell. The breakdown voltage for a tpyical lipid bilayer is about $1 \mathrm{~V}$; therefore the field strengths required to induce breakdown in a $\mathrm{K} 562$ cell $(\mathrm{r} \approx 7.5 \mu \mathrm{m})$ and in a lymphocyte $(\mathrm{r} \approx 5 \mu \mathrm{m})$ are respectively $9 \times 10^{4} \mathrm{~V} / \mathrm{m}$ and $1.3 \times 10^{5} \mathrm{~V} / \mathrm{m}$ (see eq. $\{1\}$ ). In our experiments this field strength is amply achieved (see Fig. 3A-C). In

Fig. 3. A: Survival (as defined in eq. $\{5\}$ ) of K562 cells after electrical pulsing as a function of the pulse height of the applied field. Reversing pulses (with $\mathrm{T}=100 \mu \mathrm{s}$ ) as shown in Figure 2 were used. B: Survival (as defined in eq. \{5\}) of human lymphocytes after electrical pulsing as a function of the pulse height of the applied field. Reversing pulses (with $\mathrm{T}=100 \mu \mathrm{s}$ ) as shown in Figure 2 were used. C: Survival (as defined in eq. $\{4\}$ of K562 cells (as a function of the pulse height of the applied field) if all cells are pulsed and if only every second cell is pulsed. Reversing pulses (with $T=100 \mu \mathrm{s}$ ) as shown in Figure 2 were used. 

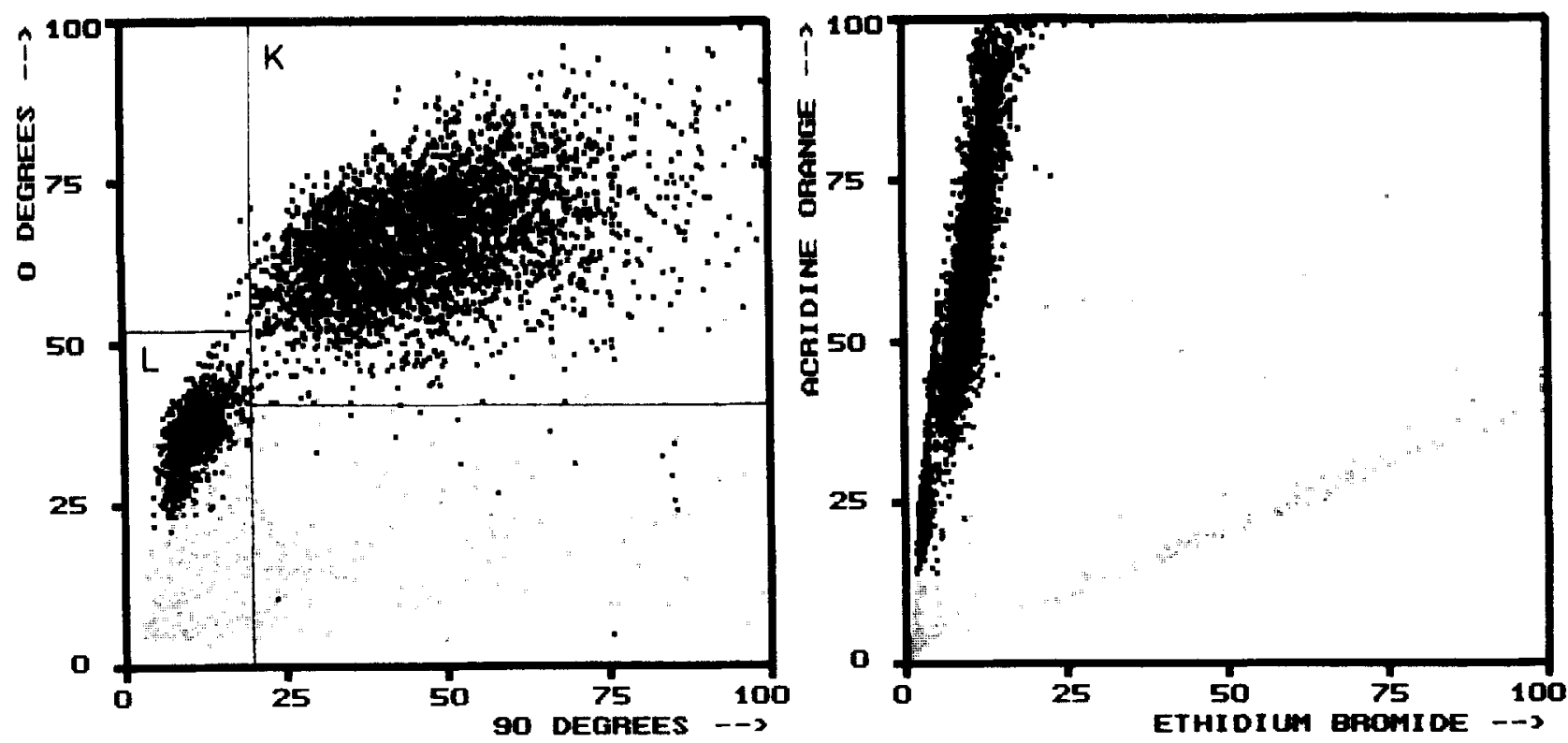

FIG. 4. Scatter plots of a mixture of K562 cells and lymphocytes. Living cells are black; dead cells are gray. $\mathrm{K}=$ living $\mathrm{K} 562$ cells $(72 \%), \mathrm{L}=$ living lymphocytes $(25 \%)$.
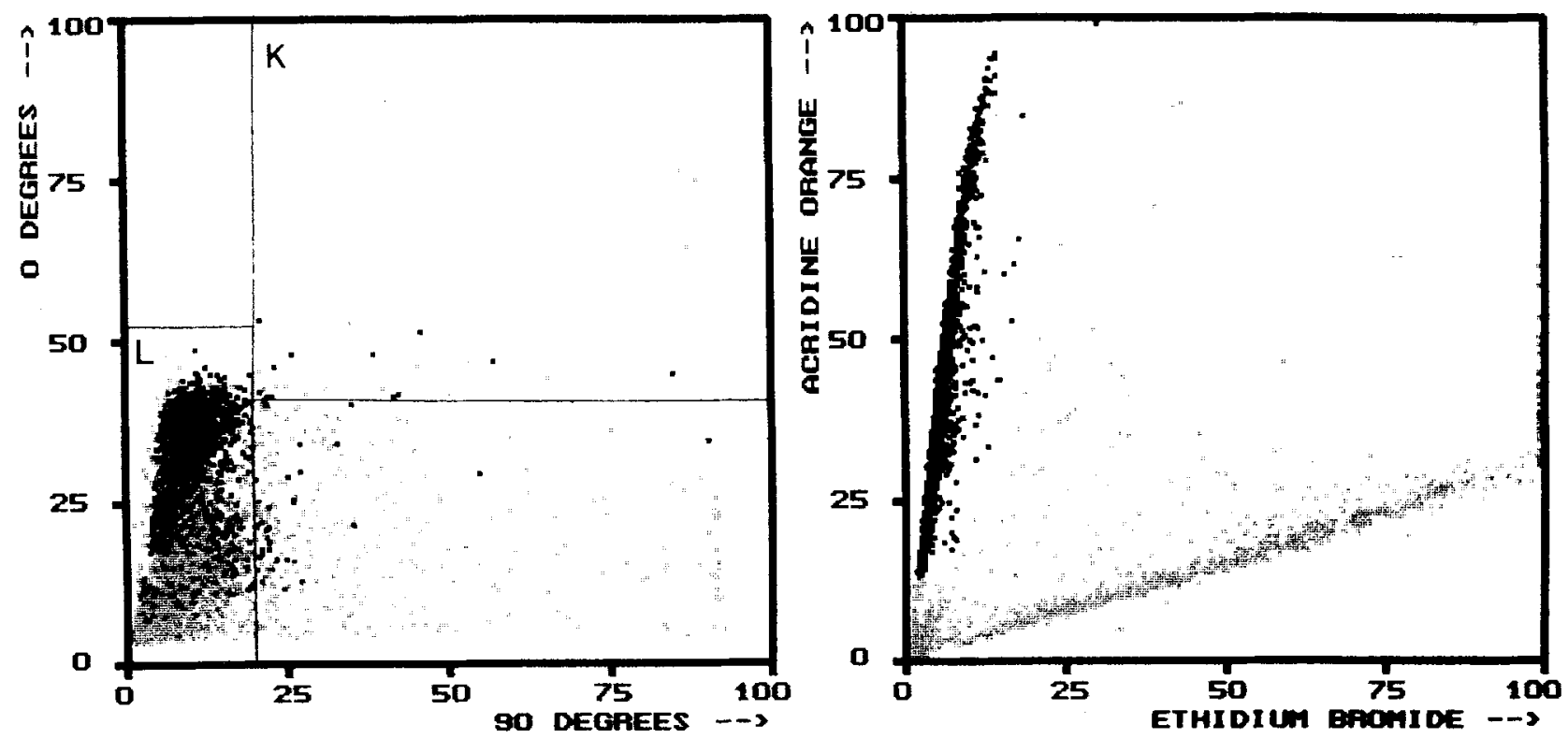

FIG. 5. Scatter plots of the sorted fraction after all K562 cells have been pulsed. Living cells are black; dead cells are gray, $\mathrm{K}=\mathrm{K} 562$ cells $(0.3 \%), \mathrm{L}=$ lymphocytes $(50,1 \%)$.

order to get irreversible breakdown long pulses and/or higher field strengths are required: the lethal effect of the electric field is proportional to the field strength and to the pulse duration (4). To achieve the same lethal effect with short pulses one therefore has to increase the field strength. To achieve more than $99 \%$ cell kill with $9 \mu$ s pulses we need field strengths that are about 24 times higher than the breakdown field strengths (see Fig. 3A-C). The height of the applied voltages and/or the minimal pulse duration, necessary to kill all cells, could probably be lowered by adding toxic chemicals to the sheath fluid or by using sheath fulid in which cells are less viable than in a physiological salt solution.

At lower field-strengths the cells do become electroporated but close again; during the time from electroporation until resealing of the membrane (toxic) molecules smaller than the pore size can enter the cells. 

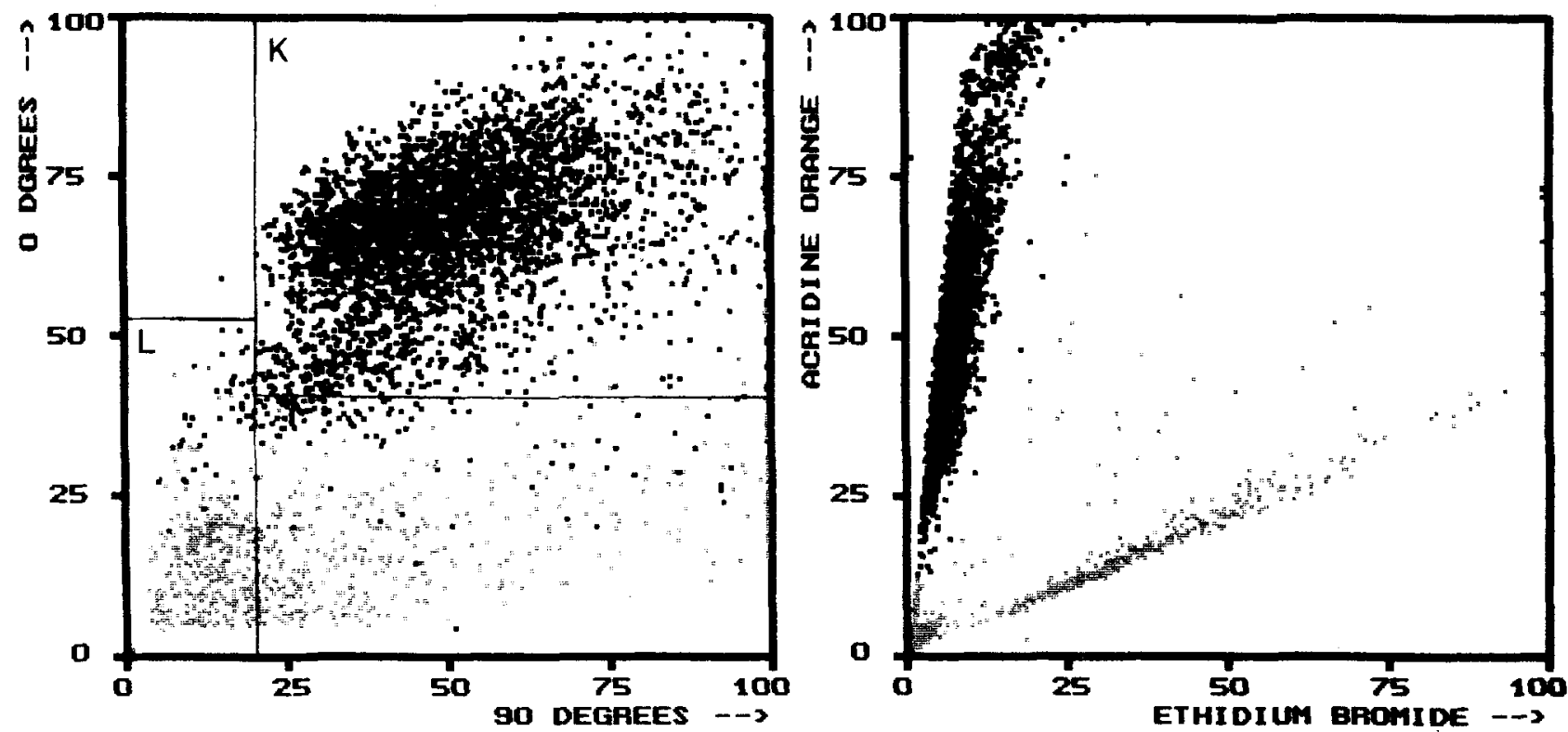

Fic. 6. Scatter plots of the sorted fraction after all lymphocytes have been pulsed. Living cells are black; dead cells are gray. $\mathrm{K}=\mathrm{K} 562$ cells $(79,9 \%), \mathrm{L}=$ lymphocytes $(0.9 \%)$.

Heat production caused by the electric current inside the orifice may also cause cell lysis if the temperature rise is too great. An estimation for the temperature rise during pulsing in the first configuration used can be made in the following way. At an applied voltage of 400 $\mathrm{V}$ (voltage at which about $50 \%$ of the lymphocytes is killed) the voltage across the orifice is about $160 \mathrm{~V}$ (see Appendix A). The power is $\mathrm{P}=\mathrm{V}^{2} / \mathrm{R}=160^{2} /\left(18.2 \cdot 10^{3}\right)$ $=1.4 \mathrm{~W}$; the mass flux is $\mathrm{Q}_{\mathrm{m}}=\rho \cdot \mathrm{v} \cdot 0=$ $1.10^{3} \cdot 10 \cdot \pi \cdot\left(35 \cdot 10^{-6}\right)^{2}=3.8 \cdot 10^{-5} \mathrm{~kg} / \mathrm{s}$. Thus the produced heat per $\mathrm{kg}$ is $\mathrm{H}=\mathrm{W} / \mathrm{Q}_{\mathrm{m}}=3.7 \cdot 10^{4} \mathrm{~J} / \mathrm{kg}$.

With the specific heat of water $\mathrm{C}=4.2 \cdot 10^{3} \mathrm{~J} /(\mathrm{kg} \cdot \mathrm{K})$ one calculates a heat rise of $\Delta \mathrm{T}=\mathrm{H} / \mathrm{C}=9^{\circ} \mathrm{K}$ across the orifice. This temperature rise is too small to be the main cause of cell lysis but could contribute to the killing process especially at higher voltages.

The third possible cause of cell lysis is the effect of shear and/or turbulent forces that act on the cell during the pulse and immediately afterwards when the cells stream into a wider region. This is not the main cause (if no pulse is given the cells survive) but in combination with the decrease in membrane stability (caused by the breakdown of the membrane) it could reinforce the formation of irreversible pores and membrane ruptures.

With simple equipment we could selectively kill $99.9 \%$ of a given K562 population. We believe that this is not the ultimate limit. Lower survival levels will be obtained by applying higher fields or different flow conditions. The total process of optical detection and electroporation takes about $200 \mu \mathrm{s}$ in the second configuration. The maximum sorting rate in the present apparatus is dependent on the analyzing speed, discrimination speed, and on the minimal pulse duration required to kill the cells.
Due to the design of the flow cell the field-strength in the orifice at the time of the pulse is more than 40 times the field-strength anywhere else in the first flow cell and more than 16 times in the second one. (The field-strength is inversely proportional to the cross section; see eq. $\{$ A2 $\}$ of Appendix A.) The critical membrane potential is only exceeded for cells in the orifice at the time of the pulse. To avoid the killing of cells outside the orifice, the field-strength in the rest of the flow cell should at least be 10 times smaller than the field-strength inside the orifice (see Fig. 3A,B). This means that the cross section of the flow channel, which is the next most narrow part of the flow cell, should be at least $\mathbf{1 0}$ times the cross section of the orifice; therefore the flow speed in the flow channel must be at least 10 times smaller than the flow speed inside the orifice.

With a flow speed of $10 \mathrm{~m} / \mathrm{s}$ inside the orifice (pulse duration $10 \mu \mathrm{s}$ ), the maximum flow speed in the new flow channel is $1 \mathrm{~m} / \mathrm{s}$. The coincidence probability $P$ for two cells to arrive at the measuring point within the dead time $t$ can be calculated by using a Poisson distribution (9): $P=1-\mathrm{e}^{-\beta \cdot t}$, where $\beta$ is the number of cells measured per second. The maximum achievable sorting rate in the present type of setup, with a coincidence probability (no multiple coincidences considered) less than $10 \%$ and a dead time of $10 \mu \mathrm{s}$ (analyzing time), is about 10,000 cells per second. The dead time in our present setup is about $20 \mu \mathrm{s}$ and we managed to kill $95 \%$ of the K562 cells present in the mixture of $\mathrm{K} 562$ cells and lymphocytes, at 5,000 cells per second.

\section{LITERATURE CITED}

1. Böyum A: Isolation of mono nuclear cells and granulocytes from human blood. Paper IV. Scand J Clin Lab Invest 21 (Suppl 97): $77-89,1968$. 
2. Herweijer H, Stokdijk W, Visser JWM: High speed photo damage cell selection using Bromodeoxyuridine/Hoechst 33342 photo sensitized cell killing. Cytometry 9:143-149, 1988.

3. Herwijer H: Photo Damage Cell Selection. Thesis, State University of Leiden, Leiden, The Netherlands, 1988.

4. Hulsheger $\mathrm{H}$, Niemann EG, Potel J: Killing bacteria with electric pulses of high field strength. Radiat Environ Biophys 20:53-65, 1981.

5. Kachel V: Electrical resistance pulse sizing (Coulter sizing); In: Flow cytometry and Sorting, Melamed MR, Mullaney PF, Mendelsohn ML (eds): J. Wiley, New York, 1979, pp 61-104.

6. Peters D, Branscomb E, Dean P, Merrill T, Pinkel D, Van Dilla M, Gray JW: The LLNL high-speed cell sorter: Design features, operational characteristics, and biological utility. Cytometry 6 : $290-301,1985$.

7. Schwan HP: EM-field induced force effects. In: Interactions Between Electromagnetic Fields and Cells, Chiabrera A, Nicolini C, Schwan HP (eds): Plenum Press, New York, 1985, pp 371-389.

8. Sweet R.G: Flow sorters for biological cells. In: Flow Cytometry and Sorting, Melamed MR, Mullaney PF, Mendelsohn MF (eds): J. Wiley \& Sons, Inc., New York, 1979, pp 177-189.

9. Visser JWM, van den Engh GJ: Immunofluorescence measurements by flow cytometry. In: Immunofluorescence Technology: Selected Theoretical and Clinical Aspects, Wick G, Trail KN, Schauenstein K (eds): Elsevier Biomedical Press, Amsterdam, The Netherlands, 1982, pp 95-128.

10. Zimmerman U: Electric field-mediated fusion and related electrical phenomena. Biochim Biophys Acta 694:227-277, 1982.

\section{APPENDIX A: CALCULATION OF THE FIELD-STRENGTH INSIDE THE ORIFICE}

If edge effects of the Coulter counter-orifice on the field distribution as described in (5) are neglected the total electrical resistance of the flow cell, $R_{\text {total }}$, is the sum of the resistances of compartments and is given by:

$$
\mathrm{R}_{\text {total }}=\sum_{i} \rho_{\mathrm{fl}} \cdot \frac{\mathbf{L}_{\mathrm{i}}}{\mathrm{O}_{\mathrm{i}}}=\mathrm{R}_{\mathrm{r}}+\mathrm{R}_{\mathrm{cc}}(\Omega),
$$

$\rho_{\mathrm{fl}}=$ specific resistance of the fluid inside the flow cell,

$\mathrm{L}_{\mathrm{i}}=$ length of compartment $\mathrm{i}$,

$\mathrm{O}_{\mathrm{i}}=$ cross section of compartment $\mathrm{i}$,

$R_{c c}=$ resistance of the Coulter counter orifice,
$R_{r}=$ resistance of the rest of the flow cell (all compartments except for the orifice).

The field strength inside a compartment, $\mathrm{E}_{\mathrm{i}}$, as a function of the applied voltage $V_{\text {applied }}$ is given by:

$$
\mathrm{E}_{\mathrm{i}}=\frac{\mathrm{R}_{\mathrm{i}}}{\mathrm{R}_{\text {total }}} \cdot \frac{\mathrm{V}_{\text {applied }}}{\mathrm{L}_{\mathrm{i}}}=\rho_{\mathrm{ff}} \cdot \frac{\mathrm{V}_{\text {applied }}}{\mathrm{R}_{\text {total }} \cdot \mathrm{O}_{\mathrm{i}}} \text {. }
$$

Measurements of $R_{r}$ and $R_{\text {total }}$ of the first flow cell as a function of the radius of the orifice showed that the theoretical values of $R_{c c} / R_{\text {total }}$ were within $10 \%$ of the measured values of $\left(R_{\text {total }}-R_{r}\right) / R_{\text {total }}$.

In the first configuration we used (orifice with a radius $35 \mu \mathrm{m})$ the measured values for $R_{\text {total }}(47.4 \pm 0.5$ $\mathrm{k} \Omega)$ and for $R_{r}(28.6 \pm 0.5 \mathrm{k} \Omega)$ yield a field-strength inside the orifice:

$$
\mathrm{E}_{\mathrm{cc}}=\frac{\mathrm{R}_{\text {total }}-\mathrm{R}_{\mathrm{r}}}{\mathrm{R}_{\text {total }}} \cdot \frac{\mathrm{V}_{\text {applied }}}{\mathrm{L}_{\mathrm{cc}}}=(0.40 \pm 0.02) \cdot 10^{4} \cdot \mathrm{V}_{\text {applied }}(\mathrm{V} / \mathrm{m}) .
$$

The values, calculated with eq.s $\{\mathrm{A} 1\}$ and $\{\mathrm{A} 2\}$ for the resistances and the field-strength are: $R_{c c}=18.2 \mathrm{k} \Omega$, $\mathrm{R}_{\text {total }}=43.7 \mathrm{k} \Omega, \mathrm{E}_{\mathrm{cc}} \approx 4.10^{4} \cdot \mathrm{V}_{\text {applied }}$.

The compartment with the next highest fieldstrengh is the flow channel; this has (theoretically) a resistance of $18.4 \mathrm{k} \Omega$ and a length of $4.2 \mathrm{~mm}$ which gives a field-strength $\mathrm{E}_{\mathrm{fc}}=100 \cdot \mathrm{V}_{\text {applied }}$. Thus the fieldstrength inside the orifice is 40 times or more the fieldstrength anywhere else in the flow cell.

In the second flow cell the flow channel has a length of $1 \mathrm{~mm}$ and a cross section of $250 \times 250 \mu \mathrm{m}^{2}$. This gives a theoretical resistance of $11,2 \mathrm{k} \Omega$. By using the same Coulter orifice, this gives a field-strength inside the orifice that is 16 times greater than the fieldstrength in the flow channel. For the total resistance of the second flow cell we measured $R_{\text {total }}=(41.2 \pm 0.5)$ $\mathrm{k} \Omega$; for the rest resistance we measured $R_{\mathrm{r}}=(22,2 \pm$ $0.5 \mathrm{k} \Omega$ ). Equation $\{\mathrm{A} 2\}$ for the field-strength inside the orifice yields:

$$
\mathrm{E}_{\mathrm{cc}}=\frac{\mathrm{R}_{\text {total }}-\mathrm{R}_{\mathrm{r}}}{\mathrm{R}_{\text {total }}} \cdot \frac{\mathrm{V}_{\text {applied }}}{\mathrm{L}_{\mathrm{cc}}}=(0.46 \pm 0.02) \cdot 10^{4} \cdot \mathrm{V}_{\text {applied }}(\mathrm{V} / \mathrm{m}) .
$$

